\title{
Preservation of the Facial Artery during Submandibular Gland Resection: Preoperative Sonographic Assessment of Facial Artery
}

\author{
Hyung Joon Choi, Sung Hoon Ryu, Hyung Min Lee, Ji Hoon Park, \\ Jin Hwan Kim, and Dong Jin Lee \\ Department of Otorhinolaryngology-Head and Neck Surgery, Kangnam Sacred Heart Hospital, Hallym University College of Medicine, \\ Seoul, Korea
}

술 전 초음파 영상을 이용한 안면동맥의 주행 확인 및 이를 이용한 악하선 절제술 시의 안면동맥의 보존

최형준 · 류성훈 · 이형민 · 박지훈 · 김진환 · 이동진

한림대학교 의과대학 강남성심병원 이비인후-두경부외과학교실

Received March 3, 2015

Revised April 17,2015

Accepted May 1, 2015

Address for correspondence

Dong Jin Lee, MD, PhD

Department of Otorhinolaryngology-

Head and Neck Surgery,

Kangnam Sacred Heart Hospital,

Hallym University

College of Medicine,

1 Singil-ro, Yeongdeungpo-gu,

Seoul 150-950, Korea

Tel $+82-2-829-5216$

Fax $+82-2-842-5217$

E-mail djlee@hallym.or.kr
Background and Objectives The traditional surgical method for submandibular gland resection includes ligation of facial artery. In this study, we used ultrasound preoperatively and tried to preserve the facial artery if facial artery passed on an extra-glandular course with a glandular branch.

Subjects and Method Patients undergoing submandibular gland resection either because of submandibular gland tumor or submandibular gland stone were prospectively included. Preoperative sonographic assessment was done to evaluate the intra-glandular or extra-glandular course of facial artery. For the cases with extra-glandular course with a glandular branch of facial artery, we tried to preserve facial artery by ligation of the glandular branch.

Results A total of 34 cases were included in this study. Among them, 6 cases (17\%) hadfacial artery passing on an extraglandular course with glandular branching. For these 6 cases, we easily could find the facial artery and glandular branch in the operative field and were able to preserve the facial artery. For the remaining 28 cases, however, the facial artery penetrated through the submandibular gland, thus we opted for the ligation of facial artery rather than preserving it to minimize bleeding or trauma during the surgery. There were no statistic difference between two groups with respect to clinical and surgical variables.

Conclusion Extra-glandular course of facial artery was easily assessed by preoperative ultrasound. In those cases, we could preserve facial artery easily without bleeding or trauma to the submandibular gland by ligation of glandular branch. As facial artery is animportant vessel for reconstruction and facial rejuvenation, it is preferable to preserve this artery if the course of this artery makes it possible to preserve. Korean J Otorhinolaryngol-Head Neck Surg 2015;58(8):558-62

Key Words Facial artery preservation · Glandular branch · Submandibular gland · Ultrasound.

\section{서 론}

악하선 절제술은 이비인후과 두경부 영역에서 많이 시행 되는 수술 중 하나로 악하선 또는 악하선관 근위부의 타석 이 원인이거나 악하선에 발생한 양성 혹은 악성 종양, 그리고
두경부 종양에서 경부절제술의 일부분으로 시행되고 있다. 악하선 절제술은 술자마다 수술 방법이 조금씩 다를 수 있지 만 안면동맥을 공여 혈관으로 사용하고자 하는 경우를 제외 하면 대부분 악하선의 상측과 외측에서 안면동맥을 각각 결 찰한 후 악하선을 절제하는 방법을 주로 이용하고 있다.1) 해 
부학적으로 안면동맥은 외경동맥에서 상갑상선동맥, 상행인 두동맥, 설동맥 다음으로 분지하여 악하선의 외측에서 악하 선을 관통하면서 악하선에 혈류를 공급한 후 악하선 상측으 로 나와서 다시 하악골 위로 주행한다. ${ }^{2,3)}$ 그러나 실제로 악하 선 절제술을 시행하는 경우 안면동맥이 악하선을 관통하지 않고 악하선 분지를 내면서 악하선 외측에서 상측으로 따로 주행하는 경우를 적지 않게 볼 수 있다. ${ }^{4}$ 이러한 경우에는 악 하선 분지만 결찰하면 안면동맥을 희생하지 않고 보존하면서 간단하게 악하선을 절제할 수 있다. 안면동맥은 두경부 외과 영역에서 유리 피판 재건 시에 주로 이용되기도 하지만 미용 수술의 관점에서도 안면의 혈류를 공급하는 중요 혈관으로 안면동맥을 희생하는 경우 반대측에서 혈류를 공급받아야 하기 때문에 여러 가지 미용적 시술에 예상치 못한 허혈성 부 작용을 유발할 수도 있다. ${ }^{1-5)}$ 그러나 이러한 부작용을 막고자 모든 악하선 절제술에서 안면동맥을 보존하는 것은 수술 시 간도 오래 걸릴 뿐만 아니라 악하선 종물이 있는 경우 종양학 적으로도 좋지 않은 결과를 유발할 수 있다.

안면동맥의 악하선 바깥 주행 및 악하선 분지의 확인은 술 전 초음파를 이용해서 쉽게 확인이 가능하다. ${ }^{6)}$ 저자들은 악 하선 절제술이 예정되어 있는 환자들에서 술 전 초음파를 시 행하여 안면동맥의 주행이 악하선을 관통하지 않는 악하선 바깥 주행을 보이고, 안면동맥으로부터의 악하선 분지가 확인 되는 경우 악하선의 외측 및 상측에서 안면동맥을 결찰하는 고식적 수술 방법 대신에 안면동맥의 악하선 분지만을 결찰 하는 방법으로 안면동맥을 보존하고자 하였으며, 이러한 수 술적 방법과 안면동맥을 희생하는 고식적 수술 방법과의 차 이를 수술시간, 배액관 양의 관점에서 비교하여 수술의 용이 도의 차이를 분석하고자 하였다.

\section{대상 및 방법}

\section{대 상}

2012년 7월부터 2014년 2월까지 악하선 질환 또는 경부절
제술의 일부분으로 악하선 절제술을 시행받은 환자 79 명 중 에서 악하선 타석증 또는 악하선 종물로 진단 받고 술 전 초 음파 상에서 안면동맥의 주행이 악하선을 관통하는지 악하선 바깥으로 주행하는지가 명확하게 판단이 가능했던 환자 34 명을 대상으로 전향적으로 연구하였다. 경부절제술의 일부로 시행된 악하선 절제술, 악성 종양이 의심되는 경우의 악하선 절제술, 술 전 초음파를 시행하지 않았거나 초음파상에서 악 하선과 안면동맥과의 관계가 명확하지 않은 경우에는 대상 에서 제외하였다.

\section{술 전 초음파 영상 및 수술 방법}

대상에 포함된 모든 환자는 수술 전 경부 초음파(Accuvix V10, Medison ${ }^{\circledR}$, Seoul, Korea)를 시행하였고, 초음파상에서 안면동맥의 악하선 바깥 주행이 확인되고 악하선 분지가 확 인된 경우에는 수술 시에 안면동맥을 희생하지 않고, 악하선 분지만 결찰함으로써 안면동맥을 보존하는 수술을 시행하였 다(Fig. 1). 반면 술 전 초음파에서 안면동맥의 주행이 악하선 을 관통하는 경우에는 악하선의 상측과 외측에서 안면동맥을 결찰하여 안면동맥을 희생하는 고식적인 수술 방법을 선택하 였다(Fig. 2).

\section{두 군 간의 차이 분석 및 통계적 방법}

안면동맥의 주행 경로에 따라 두 군으로 나누고 임상적 특성 과 수술적 용이성에 관하여 통계학적으로 분석하였다. 임상적 특성은 두 군 간에 연령, 성별, 병변의 좌우 위치 및 진단명에 따라서 차이가 있는지를 분석하였고 수술적 용이성을 비교하 기 위해 피부 절개부터 피부 봉합까지 걸린 시간과 수술 후 첫 24시간 동안에 배액 된 배액량을 비교 분석하였다. 연령은 40 세 이상과 미만으로 나누어 비교하였다. 통계분석은 SPSS(version 12.0; SPSS Inc., Chicago IL, USA)를 사용하였고 임상 적 특징의 비교에는 비연속변수 분석인 카이제곱 검정(chisquare test), 수술의 용이성과 관련된 분석에는 비모수적 평균 치 비교인 만-위트니 유 검정(Mann-Whitney U test)을 시행
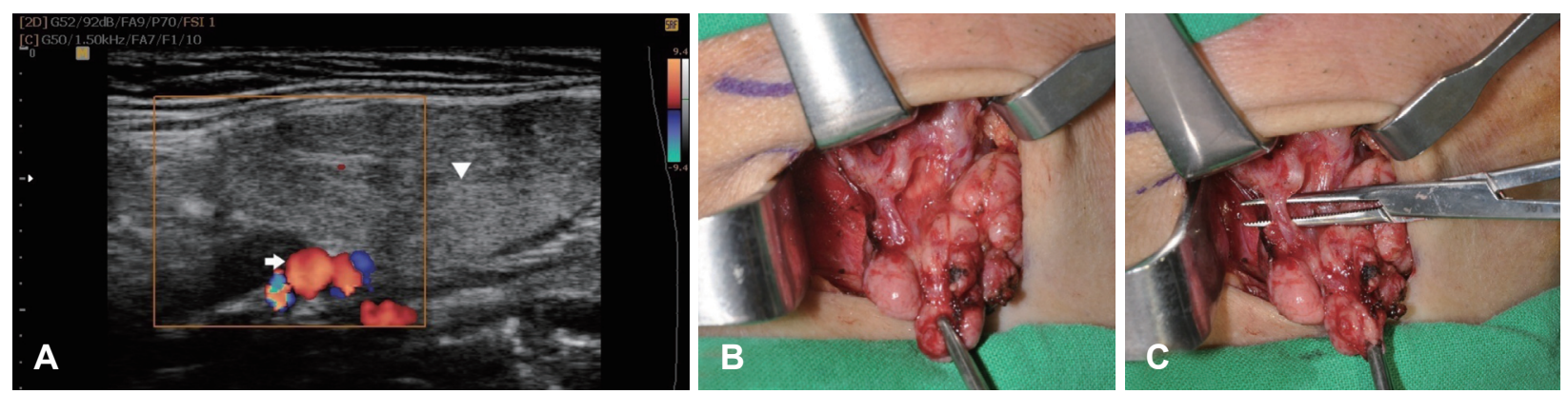

Fig. 1. Extraglandular facial artery and glandular branch. Showed preoperative ultrasound finding of extraglandular course of right facial artery and glandular branch. Facial artery (arrow), submandibular gland (arrow head) (A). Showed intraoperative finding of facial artery and glandular branch of facial artery (B and $\mathrm{C})$. 

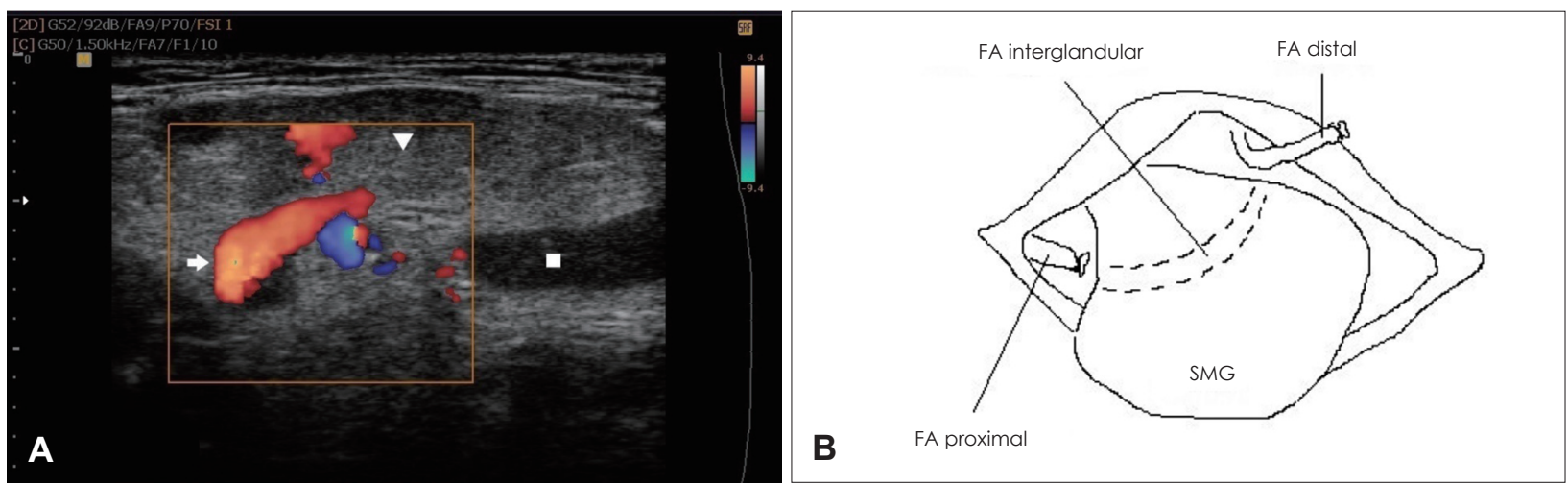

Fig. 2. Intraglandular course of facial artery. Showed preoperative ultrasound finding of intraglandular course of right facial artery. Facial artery (arrow), SMG (arrowhead), mylohyoid muscle (square) (A). Showed classic technique of SMG resection with distal and proximal facial artery ligation (B). SMG: submandibular gland, FA: facial artery.

Table 1. Subject characteristics ( $n=34$ cases)

\begin{tabular}{lll}
\hline & $\mathrm{n}$ & $\%$ \\
\hline Sex & 17 & 50 \\
$\quad$ Male & 17 & 50 \\
Female & & \\
Age & 23 & 68 \\
$\quad \geq 40$ & 11 & 32 \\
$\quad<40$ & & \\
Site & 14 & 41 \\
$\quad$ Right & 20 & 59 \\
Left & & \\
Diagnosis & 23 & 68 \\
$\quad$ Sialoadenitis & 11 & 32 \\
Benign tumor & & \\
Facial artery course & & 82 \\
Intraglandular & 28 & 18 \\
Extraglandular & 6 & \\
\hline
\end{tabular}

Table 2. Comparison between two groups

\begin{tabular}{|c|c|c|c|}
\hline & $\begin{array}{l}\text { Extraglandular } \\
\text { facial artery }\end{array}$ & $\begin{array}{l}\text { Intraglandular } \\
\text { facial artery }\end{array}$ & $p$ value \\
\hline Age & & & $0.365^{*}$ \\
\hline$\geq 40$ & 5 & 18 & \\
\hline$<40$ & 1 & 10 & \\
\hline Sex & & & $0.368^{*}$ \\
\hline Male & 2 & 15 & \\
\hline Female & 4 & 13 & \\
\hline Site & & & $0.162 *$ \\
\hline Right & 4 & 10 & \\
\hline Left & 2 & 18 & \\
\hline Diagnosis & & & $0.365^{*}$ \\
\hline Sialoadenitis & 5 & 18 & \\
\hline Benign tumor & 1 & 10 & \\
\hline $\begin{array}{l}\text { Mean OP time } \\
\text { (incision to closure) }\end{array}$ & 49 & 51 & $0.439^{\dagger}$ \\
\hline $\begin{array}{l}\text { Mean Hemovac } \\
\text { amount } \\
\left(1^{1^{s t}} 24 \text { hours }\right)\end{array}$ & 28 & 24 & $0.551^{\dagger}$ \\
\hline
\end{tabular}

*chi-square test, tMann-Whitney U test
하였다. $p$ 값이 $<0.05$ 일 때 통계적으로 유의하다고 평가하였다.

\section{결 과}

총 34명이 대상에 포함되었고 남녀비는 1:1(17:17), 평균연령 은 44.8세(18 82)였으며 40세 이상이 23명(68\%), 40세 미만이 11 명(32\%)이었다. 14 명(41\%)에서 우측 악하선 절제술을, 20명 (59\%)에서 좌측 악하선 절제술을 시행하였다(Table 1). 23명 (68\%)에서 악하선 타석증으로 수술을 시행하였으며 11명 (32\%)에서 악하선 양성 종물 진단 하에 수술을 시행하였다. 수술 전 초음파에서 안면동맥의 주행이 악하선 바깥으로 주행 하는 경우가 6명(18\%), 악하선을 관통하는 경우가 28명(82\%) 에서 관찰되었다(Table 1).

안면동맥의 주행에 따라 두 군으로 나누고 성별, 연령, 병 변의 좌우 위치 및 진단을 비교하였을 때 남녀 성별에 따른 통계학적 차이나 40 세 이상 군과 40세 미만 군에서의 차이, 병 변의 좌 우에 따른 차이 또는 악하선 타석증으로 수술한 군과 양성 악하선 종양으로 수술한 군에서의 통계적으로 유의한 차이는 보이지 않았다(Table 2). 또한 두 군 간의 피부절개에 서 피부 봉합까지의 평균 수술 시간은 안면동맥이 악하선 바 깥으로 주행하는 군에서는 평균 49분, 안면동맥이 악하선을 관통하는 군에서는 평균 51분으로 통계적인 차이를 보이지 않았으며, 첫 24시간 동안의 평균 배액량을 비교하였을 때도 각각 $28 \mathrm{~mL}$ 와 $24 \mathrm{~mL}$ 로 두 군 간의 유의한 차이는 보이지 않 았다(Table 2).

\section{고 찰}

안면동맥은 안면 혈류의 대부분을 공급하며 두경부 외과 영역의 재건수술에서 가장 많이 사용되는 공여 혈관 중 하나 이고,) 여러 가지 성형 수술 및 미용 시술 시에 빠른 회복과 
좋은 결과를 얻는 데 있어서 중요한 혈관이다.,5) 악하선 절제 술은 이비인후과 영역에서 많이 시행되는 수술이며 주로 악 하선 타석증이나 악하선에 발생한 종양, 그리고 경부절제술 의 일부에 포함되어 시행되고 있다. 지금까지 시행되고 있는 고 식적인 악하선 절제술은 안면동맥의 원위부와 근위부를 결찰 하는 과정이 포함되어 일측 안면동맥을 희생하게 된다. 일측 안면동맥이 희생되더라도 반대측 안면동맥에서 혈류를 공급 받기 때문에 대부분에서 큰 문제를 일으키지는 않으나, 추후 에 미용적인 수술을 받거나 두경부 재건술이 시행되어야 하는 경우 이러한 안면동맥의 희생이 결과에 많은 영향을 줄 수 있 다. ${ }^{2-5)}$ 그렇다고 모든 경우에서 안면동맥을 보존하고자 하여 안면동맥이 악하선을 관통하는 경우에도 안면동맥을 끝까지 따라가면서 박리하다 보면, 안면동맥을 보존할 수는 있겠지만 염증이 심한 경우나 종양학적 관점에서 볼 때 수술시간이 길 어지고 종양세포의 주변 파급을 유발하게 되어 바람직하지 않은 결과를 가져올 수도 있다. ${ }^{1)}$

악하선 절제술 수술 술기가 익숙한 술자에서는 수술 시에 전체적인 악하선의 형태와 안면동맥의 주행을 확인하여 술 전 초음파 시행여부와 상관없이 안면동맥의 악하선 바깥 주행을 확인하고 안면동맥을 보존하는 것이 가능할 수도 있겠으나 수 술 술기가 익숙하지 않은 술자일 경우나, 염증으로 인한 악하 선과 주변 연조직과의 유착 정도가 심한 경우에는 악하선의 상 부가 하악골 하부 연조직에서 어느 정도 박리가 되어야 악하선 을 앞쪽 또는 뒤쪽으로 당기면서 추가적인 박리가 가능해지기 때문에 우선적으로 악하선 상부를 박리하게 되는데 이 과정에 서 안면동맥의 원위부를 결찰하게 되는 경우가 많다.

이 연구에서 저자들은 악하선 절제술이 예정되어 있는 환 자들에서 수술 전 초음파를 시행하여 안면동맥의 주행이 악 하선을 관통하지 않는 악하선 바깥 주행을 보이고 안면동맥으 로부터의 악하선 분지가 확인되는 경우, 악하선의 외측 및 상 측에서 안면동맥을 결찰하는 고식적 수술 방법 대신에 안면동 맥의 악하선 분지만을 결찰하는 방법으로 안면동맥을 보존하 고자 하였으며, 이러한 수술적 방법과 안면동맥을 희생하는 고식적 수술 방법과의 차이를 수술시간, 배액관 양의 관점에 서 비교하여 수술의 용이도의 차이를 분석하고자 하였다.

수술 전 초음파 검사를 시행하여 안면동맥이 악하선을 관통 하지 않고 악하선 바깥으로 주행하면서 악하선 분지를 내는 경우는 전체 34명 중 6명의 환자(18\%)에서 확인할 수 있었다. 이 러한 6 명의 환자에서는 안면동맥의 근위부와 원위부를 결찰하 여 안면동맥을 희생하는 고식적인 수술방법 대신 안면동맥의 악하선 분지를 결찰하여 안면동맥을 보존하는 수술 방법을 시 행하였으며 6명 모두에서 안면동맥을 쉽게 보존할 수 있었다. 두 그룹 간의 임상적 변수와 수술시간 및 배액량 등을 비교하
였을 때 두 수술 방법 간의 유의한 차이는 보이지 않았다.

실제로 안면동맥의 안면 혈류공급에 대한 중요성이 인식되 면서 악하선 절제술 시에 안면동맥을 보존하고자 하는 연구들 이 있었다.18,9) Talmi 등은 104 명의 환자를 대상으로 116 개의 악하선 절제술을 시행하면서 모든 경우에서 안면동맥을 보존 하고자 하였는데 이 중 81개의 악하선 절제술에서 안면동맥을 보존하였다고 보고하였다. 그러나 어떤 경우에 안면동맥의 보 존이 가능하였고 어떤 경우에 보존이 불가능하였으며 이러한 보존적인 수술 방법을 고식적인 수술 방법과 비교할 때 어떠한 장단점이 있는지에 대한 분석은 연구에 포함되지 않았다. ${ }^{1)}$ 이 연구에서는 기존 연구에서와는 다르게 모든 경우에서 안면동 맥을 보존하려고 하지 않고, 수술 전 초음파를 시행하여 쉽게 안면동맥의 보존이 가능한 경우를 선택할 수 있는 방법을 찾 아내고자 하였다. 기존의 연구에서처럼 모든 경우에서 안면동 맥을 보존하고자 하여 악하선을 안면동맥의 주행에 따라 절 개하지 않고, 악하선을 관통하는 경우에는 악하선의 상측과 외측에서 안면동맥을 결찰하는 고식적인 방법으로 수술을 시 행하였고, 술 전 초음파에서 안면동맥이 악하선 바깥으로 주 행하는 것이 확인된 경우에만 안면동맥의 악하선 분지를 결 찰하여 비교적 쉽게 안면동맥을 보존하고자 하였다.

영상학적 기법의 발달로 높은 해상도의 초음파가 보급되면 서 이전에는 관찰하기 어려웠던 작은 구조물까지도 세밀하게 관찰이 가능하게 되었다.10,11) 특히 도플러 초음파를 이용하면 서 혈류의 흐름과 작은 혈관 분지들까지 관찰이 가능해졌고 컴퓨터단층촬영과 자기공명영상 기법이 함께 발달하면서 두 경부에 분포하는 작고 복잡한 구조물들에 대한 해부학적인 연구가 많이 진행되었다. ${ }^{12-15)}$ 이 연구에서도 2-D 도플러 초음파 를 이용하여 안면동맥이 외경동맥에서 분지하는 지점에서부 터 악하선으로 들어가는 부위까지 자세한 관찰이 가능하였 고, 여기에서 안면동맥이 악하선을 관통하는지, 아니면 악하 선 바깥으로 주행하면서 악하선 분지를 내는지를 쉽게 확인 할 수 있었다. 또 초음파 결과에 따라 수술방법을 다르게 하 여 가능하면 악하선 절제술을 시행하면서도 안면동맥을 쉽 게 보존하고자 하였다. 이 연구에서는 악하선과 안면동맥의 관계가 초음파상으로 불명확하여 연구에서 제외된 경우가 상 당히 많았으나, 좀 더 높은 해상도의 초음파를 이용한다면 더 많은 환자가 연구에 포함되었을 것이다.

이 연구는 악하선 절제 수술이 예정되어 있는 환자군에서 수술 전 초음파 검사를 시행하여 안면동맥을 보존할 수 있는 악하선 절제 수술 방법을 전향적으로 제시하는 첫 번째 연구 라는 점에서 의의가 있다. 그러나 이 연구에 포함된 환자군 수 가 상대적으로 적고, 초음파 검사의 특성상 검사자의 주관적 인 판단이 개입될 수 있다는 면에서 단점이 될 수 있으며, 이는 
보다 객관적인 영상학적 검사법의 활용과 더 많은 환자 수가 연구에 포함된다면 더 정확하고 유용한 결과를 얻을 수 있을 것으로 생각된다.

이 연구에서 저자들은 안면동맥의 악하선 바깥 주행을 수 술 전 초음파에서 확인하여 이러한 경우 악하선 절제 수술 시 에 안면동맥의 악하선 분지를 결찰함으로써 쉽게 안면동맥을 보존할 수 있었다. 안면동맥은 두경부 외과 영역에서 공여 혈 관으로 이용될 뿐만 아니라 미용수술에서도 혈류를 담당하 는 중요한 혈관이기 때문에 수술 전 초음파에서 안면동맥의 악하선 바깥 주행이 확인되면 안면동맥의 근위부와 원위부를 결찰하여 안면동맥을 희생하는 고식적 수술 방법 대신 악하 선 분지를 결찰하여 안면동맥을 보존하는 수술 방법이 환자 에게 있어서 더 좋은 수술 방법이 될 것으로 생각된다.

\section{REFERENCES}

1) Talmi YP, Wolf M, Bedrin L, Horowitz Z, Dori S, Chaushu G, et al. Preservation of the facial artery in excision of the submandibular salivary gland. Br J Plast Surg 2003;56(2):156-7.

2) Li L, Gao XL, Song YZ, Xu H, Yu GY, Zhu ZH, et al. Anatomy of arteries and veins of submandibular glands. Chin Med J (Engl) 2007;120(13):1179-82.

3) Eid N, Ito Y, Otsuki Y. Anomalous branching pattern of external carotid artery: clinical relevance to cervicofacial surgery. Clin Anat 2011;24(8):953-5.

4) Vadgaonkar R, Rai R, Prabhu LV, Bv M, Samapriya N. Variant facial artery in the submandibular region. J Craniofac Surg 2012;23 (4):e355-7.

5) Touré G, Meningaud JP. Anatomical study of the vascular territories of the maxilla: role of the facial artery in allotransplantation. J Plast Reconstr Aesthet Surg 2015;68(2):213-8.

6) Gervasio A, D’Orta G, Mujahed I, Biasio A. Sonographic anatomy of the neck: the suprahyoid region. J Ultrasound 2011;14(3):130-5.

7) Joo YH, Sun DI, Park JO, Cho KJ, Seo JH, Park JW, et al. Analysis of recipient vessel for microvascular reconstruction of the head and neck. Korean J Otorhinolaryngol-Head Neck Surg 2010;53(1):20-3.

8) Xu H, Mao C, Liu JM, Peng X, Zhu ZH, Yu GY. Microanatomic study of the vascular and duct system of the submandibular gland. J Oral Maxillofac Surg 2011;69(4):1103-7.

9) Ching AS, Ahuja AT. High-resolution sonography of the submandibular space: anatomy and abnormalities. AJR Am J Roentgenol 2002;179(3):703-8.

10) Wojtczak JA. Submandibular sonography: assessment of hyomental distances and ratio, tongue size, and floor of the mouth musculature using portable sonography. J Ultrasound Med 2012;31(4):523-8.

11) Alagöz MS, Uysal AC, Tüccar E, Sensöz O. The vascular anatomy of the digastric muscle. J Craniofac Surg 2004;15(1):114-7.

12) La'porte SJ, Juttla JK, Lingam RK. Imaging the floor of the mouth and the sublingual space. Radiographics 2011;31(5):1215-30.

13) Lee JH, Lee BN, Kwon SO, Chung RH, Han SH. Anatomical localization of submandibular gland for botulinum toxin injection. Surg Radiol Anat 2010;32(10):945-9.

14) Prasad A, Yu E, Wong DT, Karkhanis R, Gullane P, Chan VW. Comparison of sonography and computed tomography as imaging tools for assessment of airway structures. J Ultrasound Med 2011;30 (7):965-72.

15) Guerrissi JO, Taborda G. Endoscopic excision of the submandibular gland by an intraoral approach. J Craniofac Surg 2001;12(3):299-303. 